\title{
Dynamics of the External Environment (Market) and Strategic Behavior of the Construction Firm
}

\author{
Aneta Marichova
}

\begin{abstract}
The dynamic changes in the external (and often inside) environment place every firm in front of serious new and unknown challenges and make it more difficult to adapt to them. Under these conditions known traditional short-term models of corporate behavior have an increasingly limited role and a chance for success. The main problem and goal of the company should be a clearly defined longterm strategy that allows building competitive advantages and performance. Therefore, the purpose of the study is to analyze the impact of a dynamic external environment (market) on strategic behavior by developing a conceptual model: "Dynamics of the external environment (market) - Strategic behavior - Competitive advantages" to be applied and tested in the activity of the construction firm.
\end{abstract}

Keywords - competitive advantages, construction firm, dynamics of the external environment (market), strategic behavior

\section{INTRODUCTION}

The study and analysis of the dynamics of the external environment and the strategic behavior of the company with a view to competitive advantages is usually a problem that occupies too little space in theoretical research. Resources and distinctive company competencies are considered as assigned and determining the competitive advantages and not considering the opportunities for their development and change resulting from dynamic changes. The existing system of organization in most companies ignores such strategic issues as increasing competition, technology dynamics, consumer tastes and preferences, changes in demand, mergers and acquisitions between companies, specialization and/or diversification, increasing uncertainty in the economic environment.

In recent years, most studies determine strategic behavior and competitive advantage as a function of two factors: 1) the role and influence of the dynamics of the external environment, and 2) the development and change of firm resources and competences under the influence of external changes. In other words, every firm must seek the source of competitive advantage, both in its internal factors/resources (technology, workforce qualification, raw materials and materials used, innovation, financial resources and organizational structure) as well as in external factors (market dynamics and structure, level of concentration and competition, vertical links, supply and demand dynamics, etc.), and also in the ability to combine the development of external and internal factors/resources which can ensure the fulfillment of its goals [1]. 
In the presented research the author develops and applies the model "Dynamics of the external environment (market) - Strategic behavior - Competitive advantages", which allows developing a long-term model for company development.

In modern conditions the dynamics of the external environment (market) is a function of technology development, innovation, changes in demand, competition, regulatory mechanisms and cyclical economic development and is a major factor determining the strategic behavior of the company. In addition, dynamic market conditions determine not only the structure of the market and the level of competition, but also the development prospects and profit potential.

The strategic behavior refers to the business practices applied by a company in the industry to realize its

- competitive advantages. The strategy of each company is determined by the market structure, industry specificity and

- competitive company policies (external factors), but on the other hand it is based on internal factors (resources and distinctive competences), independent of the above. Therefore, it is necessary not only to study the influence of external factors, but also the influence of internal factors (firm resources) to realize the competitive advantages and performance.

Competitive advantages mean the ability of a firm to create, offer and realize higher value for its customers with a strategy that is not implemented by current competitors. Therefore, they are a function of strategic behavior (which in turn is a function of the dynamics of the external environment, the market and relevant market structure and company resources) and put the company in a better position than its competitors. From this point of view theoretical model (framework) "Dynamics of the external environment (market) - Strategic behavior - Competitive advantages", allows the company better understand dynamic conditions, in which he works and on that basis identify possible strategic behavior, as a broad formula for the way in which it intends to compete in order to build competitive advantage [2]. The study includes two parts: 1) development of a theoretical model: "Dynamics of the external environment (market) - Strategic behavior Competitive advantages" and formulation of working hypotheses, and 2) application of the model, testing of hypotheses in the activity of the construction firm.

\section{THEORETICAL MODEL "DYNAMICS OF THE EXTERNAL ENVIRONMENT (MARKET) -STRATEGIC BEHAVIOR - COMPETITIVE ADVANTAGES' AND RESEARCH HYPOTHESES}

New dynamic conditions impose elaboration and the application of a new theoretical framework (model) for the study of the link "Dynamics of the external environment (market) - Strategic behavior - Competitive advantages", which will be made in this chapter. In the developed model takes into account primarily the dynamics of market development and the emphasis is on the analysis of the competitive mechanism, the process of interaction between companies. Investigation of the mutual adaptation of the dynamics of the external environment (market) and firm behavior includes an analysis of the following strategic aspects:

I.Dynamics of the external environment (market):

1) Market dynamics - change in demand (tastes, preferences, incomes, substitute products), in the competitive environment (number and size of sellers and buyers, product 
differentiation), positions and behavior of companies, as well as different degree of uncertainty [3].

2) Technological dynamics related to technological changes, innovations [4], cost and productivity in the industry, market power of suppliers and buyers, threat of entry of new competitors that affect competitiveness and determine the complexity of connections in a given market (barriers to entry into the industry, vertical and horizontal links and borders).

3) Evaluation of development prospects and profit potential.

The author shares the idea, that in terms of the dynamics of the external environment, the changes and the speed with which they take place, markets can be divided into two groups [5]: markets with moderate, relatively stable dynamic development (these are usually oligopoly markets), which means changes at a moderate rate predictable managers and markets with fast dynamic, high-speed changes (this usually markets with effective monopolistic competition) which are difficult to predict by management. This suggests that different dynamics and different market conditions require managers to develop and implement different strategic solutions that have different conceptual bases.

\section{Strategic behavior of the firm.}

The strategic behavior of the company is a system of goals, policies, plans that shape the behavior of the company in the market in order to maintain a viable alignment of goals, resources and capabilities with the dynamic, changing external environment.

The purpose of each company strategy is to create and modify the company's activities and products so that they can build competitive advantages and the desired growth and profit. Particularly important aspect of the strategic behavior of each company is the constant monitoring of the processes that develop in the external environment and rapid reassessment of mission, strategy, plan, and development of internal resources, which will allow successful adaptation to the new realities. In other words, strategic behavior is related to the process of constant development of the firm's resources and competencies as a function of dynamic changes in the environment and constant adaptation of these new competencies to the changing environment, i.e. dynamic link between external and internal factors. Business decisions and strategies are the result of other companies' decisions and strategies, in response, the policy of the first company, which in practice is a dynamic process, constantly evolving over time, leading to a change in market dynamics.

In practice, strategic corporate behavior, a function of external and internal factors can be realized in the following directions:

1) Policy of strategic positioning of the company (usually in a market with an oligopolistic market structure), which includes actions related to the development of its daily business and implementation of policies, which have as their ultimate goal the protection and/or expansion of market positions, i.e. changing the horizontal and or vertical boundaries of the market and building competitive advantage. They are determined by the behavior and competitive strategies of competing firms and the competitive strategies of a given firm. The company selects and changes its boundaries by analyzing its skills and ability to create value for consumers within the defined frameworks (boundaries) of functioning. The basis for changing the market boundaries are the company activities (production, marketing, sales, etc.), which allow to realize economies of scale or from the scope of company activity.

2) Product positioning policy. The strategic behavior of the firm in order to protect and / or expand its position in the market with effective, monopolistic competition is realized through a product positioning policy, with which the company seeks to create a competitive advantage in the minds of consumers, using tangible and intangible characteristics and properties of your product compared to the next strongest competitor. 
Product positioning policy is based on effective market segmentation based on appropriately selected segmentation criteria, which take into account the specificity of the market and customers, selecting a target market and positioning the company. Differentiation of the product and its successful positioning creates competitive advantages of a company only if it manages to maintain this area of differentiation better and longer than its competitors and to obtain a return from the higher added value offered to the consumer in the form of additional profit.

3) Company policy for the development of firm resources, its distinctive competencies and the creation of a strategic resource. The firm resources (everything that a company owns) and distinctive competencies (the result of management and organizational decisions that create a unique combination of corporate resources) are the link between incoming intellectual firm resources (information, knowledge, learning, management skills) and material end result. They are the main determinants of competitive advantage, provided that they meet the following four characteristics: high value, unique, difficult to imitate by competitors and can be effectively used, which in practice means creating a strategic business resource [6]. The created strategic resource allows the company to offer higher customer value added than competitors and gain competitive advantage and profit over the industry / market average over the long term [7].

\section{Competitive advantages.}

Competitive advantages mean that the company can create and offer higher value to its customers with a strategy that is not implemented by current competitors. The company can realize competitive advantages in two directions: competitive advantage in cost differentiation (the result of economies of scale) and competitive advantage in product differentiation (leader in quality).

In practice, building competitive advantage is a function of the firm's ability to create its distinctive competences (strategic, unique resource), an effective corporate structure that in its totality and taking into account the influence of external factors, determine its strategic behavior (its present and future positions and new development guidelines) determined by history, experience, knowledge, and managerial decisions. Consequently, competitive advantages are a link between behavior, company policies, its distinctive competencies (strategic resource) and firm performance. Realizing competitive advantage is a factor in realizing higher profits, but not always realizing higher profits is an indicator of realizing competitive advantages. Therefore, the assessment of competitive advantage realized must necessarily include two different characteristics: market positions (leader in product differentiation or leader in cost differentiation) and efficiency of company activity, expressed in financial data and results [8].

Without pretending to be exhaustive, the elements included in the developed model "Dynamics of the external environment (market) - Strategic behavior - Competitive advantages" (Figure 1) are the main ones, which should be the subject of research and the basis for defining the following three hypotheses that will be empirically proven:

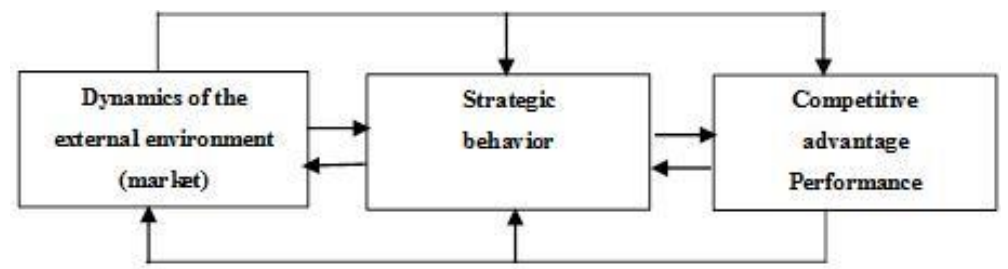

Fig. 1. Theoretical model "Dynamics of the external environment (market) - Strategic behavior - Competitive advantages" 
Hypothesis 1: The dynamics of the external environment (market) have a right, positive relationship and influence on the strategic behavior of the firm.

Hypothesis 2: The dynamics of the external environment (market) have rights, a positive connection and influence on the development of firm resources and distinctive competencies and the creation of a strategic resource.

Hypothesis 3: Competitive advantages are the link between the strategic behavior of the firm and performance.

\section{APPLICATION OF THE THEORETICAL MODEL TO STUDY THE STRATEGIC BEHAVIOR OF A CONSTRUCTION FIRM}

\subsection{Method and limitations of the study}

Many investment companies have been affected by their sales of residential units due to the large competition for the most advanced companies in terms of using modern technology cheaper than the traditional materials whose economic feasibility of using them is not useful. The sale price of residential units are $400 \$ / \mathrm{m}^{2}-1000 \$ / \mathrm{m}^{2}$ according to the quality and according to the materials used in the implementation of the work lightweight materials such as foam concrete and walls filled with isolated materials increase thermal insulation, in addition to its contribution to reduce dead loads and thus reduce the rebar and reduce the space Structural sections, which in turn contributes to reducing the total cost of housing units.

\subsection{Main results of the study}

Testing the first hypothesis "The dynamics of the external environment (market) has rights, a positive connection and influence on the strategic behavior of the firm" allows to draw the following conclusions:

Managers of firms, operating in the civil engineering market define the market as a moderately dynamic, oligopolistic market characterized by a stable industry structure, defined relatively stable horizontal and vertical boundaries, a stable number of competitors, consumers, suppliers, clear and predictable behavior of participants. In these markets, the strategic behavior of the company is implemented in accordance with the traditional concept - through detailed, analytical procedures and routine actions, the result of accumulated experience, knowledge and sufficient information. The decisions made are implemented over a long period of time after a thorough evaluation, analysis of existing alternatives, and overall the results are predictable. Procedures for assessing and analyzing the situation and developing the necessary strategic decisions are often applied, though with different variations that takes into account the specificity of the changes occurring in the external environment. This allows managers to analyze each current situation in accordance with their accumulated experience, managerial knowledge and to plan and organize their activities as a well-structured and organized analytical process that involves several sequential steps, starting with data collection, developing different alternatives, evaluation of alternatives and choices. In certain situations, in some companies these activities are carried out by individuals who have the appropriate knowledge and specialization. These practices increase company memory accumulation; they extend their routine action, which in turn facilitates subsequent procedures and their predictability. 


\section{sciendo}

92 Ovidius University Annals Series: Civil Engineering, Year 21, 2019

Managers of firms, operating in the building construction market define the market as volatile, rapidly changing without a clearly defined market structure, delineated. The participants (competitors, users, suppliers, etc.) are constantly changing, with an unclear profile, unknown actions and reactions. There is no known, well-established and wellfunctioning business model. There is a constant dynamic, change of participants and change in their behavior and structure, which puts every manager to a serious test. Under these conditions, it is difficult to analyze and evaluate the situation and make well-considered decisions. Uncertainty does not allow the creation and implementation of a long-running model for a longer period of time, although with the appropriate variations. Analysis and decisions are not the result of using knowledge, experience, but above all intuition, business sense, chance, luck and risk propencity. The results are unpredictable, the actions are on "a trial-and-error" basis and there are no stability conditions in the result. Nevertheless, the decisions and strategies implemented, though expressed in simple, singular and unambiguous actions are the basis for the development and creation of new specific knowledge, skills that are clearly difficult to apply in the next situation, which under the new conditions will be radically different and will require completely different solutions. The main factor for improving the efficiency and successful development of the company are only the managerial skills for quick analysis of the current and future situation, accompanied by chance and success.

In the markets, accompanied by high-speed changes, the main characteristic is the lack of the necessary information, time and knowledge about the new situation, which does not allow the implementation of familiar, routine actions, rules and procedures, deadlines. However, this is an auspicious time to create new specific knowledge, skills that meet the new situation. The behavioral model under these conditions is "learning by doing," not "learning before actions" and creating new opportunities in the company with low losses and quick feedback, which makes it possible to compensate for the lack of appropriate knowledge of the specific situation.

The combination of market (degree of uncertainty) and technological (degree of complexity of connections in the industry) dynamics creates different opportunities for company development and strategic behavior. The low degree of uncertainty, combined with the low degree of complexity of relationships, implies stability and a diversification strategy based on low costs and cost differentiation. The increasing degree of uncertainty and complexity in the market, require action to be development-oriented and accelerated implementation of new technologies, development of innovations, development of new, effective business models, creation new product that integrates, consolidates consumer tastes, and also consolidates the market by creating alliances, horizontal and vertical mergers, building an integrated supply chain management system through long-term relationships, supplier contracts, exchange of information with the active involvement of the end customer. Therefore, the different dynamics in the external environment (market) also determine the different strategic behavior for construction companies operating in different market segments. Firms operating in highly dynamic markets (building construction market) will be able to build competitive advantages with a product positioning strategy by differentiating the product and expanding customer service, the result of innovation, knowledge, i.e. development of intangible assets. Companies in the civil engineering market, which is defined as a market with moderate dynamics and stability, will pursue a policy of strategic positioning, which changes and defines new horizontal and/or vertical boundaries and on that basis they will build competitive advantages through differentiation in costs, the result of both traditional scale-up and economies of scale, and innovation, knowledge, i. e. development of intangible assets. 
Testing the second hypothesis proves that the dynamics of the external environment (market) have the right, positive connection and influence on the development of firm resources and distinctive competencies and the creation of strategic resource.

Changes in demand and technology, shortening the product life cycle, increasing global competition increase the dynamics of the external environment and reduce the value of the created strategic resource in the company, but also create the conditions for development, change and creation of a new strategic company resource. The most complex problem facing any company with extremely high risk is the solution to change and the search for entirely new development opportunities. A source of information, which can prompt and facilitate the company in making these important decisions, is the dynamics in the external environment. The main problem is the development of an effective monitoring system, the assessment of development opportunities and threats, the forecast of the expected changes in the external environment, the accumulation of knowledge, learning and developing strategic solutions in response to changes.

Effective use of "incoming intellectual resources/factors" (monitoring, evaluation, learning) ensures the development and implementation of new business strategies in order to absorb new knowledge and skills for new product development, implementation of new technologies, innovations, successful mergers, alliances, strategic and organizational change. The success of one company and the failure of another company operating in the same dynamics of the environment is determined by managerial decisions, which in turn are the result of their specific, individual skills, discernment in the assessment of external and internal conditions, the results achieved and the necessary and possible organizational changes.

At the same time, monitoring the external environment alone is not enough as it is possible the need for change is caused and/or for internal reasons related to dissatisfaction with company positions, current state of resources, etc. The simultaneous monitoring and evaluation of both the external and internal environment allows an assessment of the firm's ability to respond to external changes with its existing potential, either by expanding it or by creating new configurations. Therefore, even if a company has significant assets (resources) and competences, if it operates on the same scale every day, it produces the same product, sells the same in the same market, to the same customers, it can only realize short-term advantage on the basis of realized operational efficiency, the result of winning positions, building a reputation in the community and customer loyalty, in the face of increasing demand or having a defensive system in place against competitors.

Building competitive advantage can only be the result of making strategic decisions based on assimilated new knowledge and learning, which is the basis for creating a new effective combination of resources, i.e. of her distinctive competencies. They are formed and developed as a result of the collective knowledge in the organization, the specific skills for integrating and coordinating capacity, knowledge, skills and are embodied physically, in the created core products in the company or in its product portfolio, in a way that enables the realization of competitive advantages over a given period. The specific process of integrating, combining, learning and transforming (changing, reconfiguring) resources based on known practices currently creates the strategic resource and opportunities to realize and sustain competitive advantages based on flexible and adaptive management decisions and actions that allow not only to improve our own positions, but also to improve the overall market situation in the long term. 
Testing the third hypothesis allows the following conclusions - the sources of competitive advantage are:

1) External (strategic) sources of competitive advantage are a function of the firm's ability to monitoring and evaluate the dynamics in the external environment, to use the opportunities and neutralizes threats.

2) Internal sources of competitive advantage are the result of the development of the company resources (history, experience, reputation, knowledge, routine, etc.), organizational skills and innovative activity, which shape its distinctive competencies and its ability to create strategic resource.

The relationship between external and internal resources for the purpose of building competitive advantage is realized by three main factors, defined as the adaptive, absorbing and innovative capacity of the company and the managers. The three factors for building competitive advantage are related, but conceptually different. Adaptive capability is related to the ability of the company to adapt to changes in the environment, through the flexibility of resources and the alignment of internal and external factors and capabilities. Absorbing ability develops the skills to absorb new knowledge, combine external and internal knowledge and use it effectively. The innovative ability directs the company to develop new products, services, markets and the relationship between them. Although common to all companies, these three factors evolve differently, uniquely within each company, which turns them into a source, not just of competitive advantage, but of sustainable advantage. Therefore, "the adaptive, absorbent and innovative capacity of the company are the main factors, components that provide a constant opportunity for the company to integrate, reconfigure, renew, develop and change its resources in accordance with changes in the external environment" [10]. In other words, the relationship between behavior, resources, competencies and the external environment determines the strategic choice of the company, its positions and competitive advantages - differentiation in the product or differentiation in costs and allows the achievement of the ultimate goals. Choosing a product differentiation strategy means concentrating on innovation capability, and choosing cost differentiation means focusing on absorbent and adaptive capability that enables efficient low-cost production to be created.

The analysis of the dynamics of the external environment (market) and internal sources for building competitive advantages allow us to deduce two exemplary models of building competitive advantages:

1) A model of building competitive advantage in an unstable, fast-changing market, with an effective monopolistic structure (building construction market), without clearly defined boundaries, changing participants, unknown actions and reactions, which implies product differentiation policy and competitive advantages in differentiating product (Figure2).

2) Model of building competitive advantage in a moderately dynamic, oligopolistic market (civil engineering market), with a stable industry structure, relatively stable horizontal and vertical boundaries, a stable number of competitors, consumers, suppliers, clear and predictable behavior of participants, which implies a policy of strategic positioning and competitive advantages in cost differentiation. (Figure 3). 


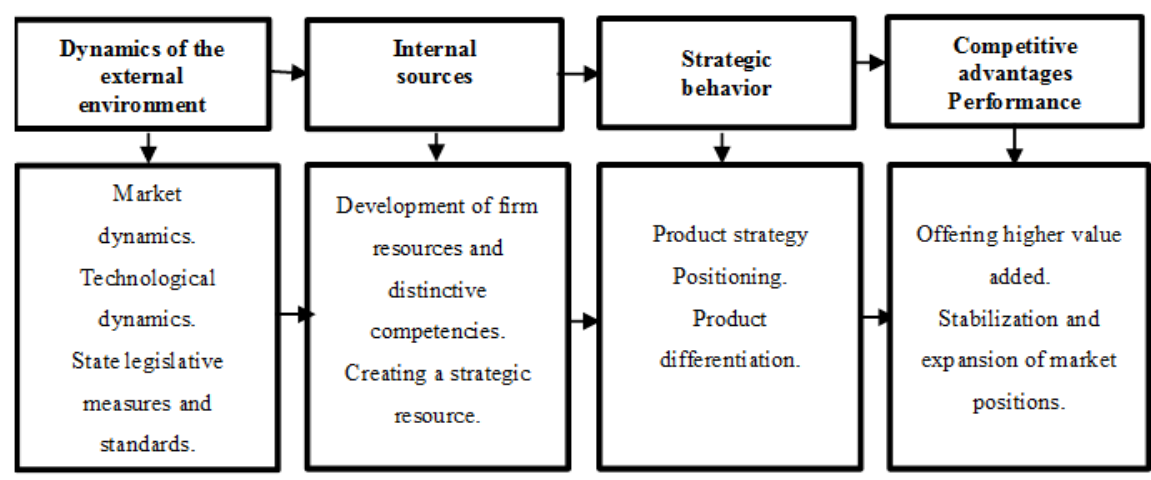

Fig.2. A model of building competitive advantage in an unstable, fast-changing market, with an effective monopolistic market structure (building construction market), which implies product differentiation policy

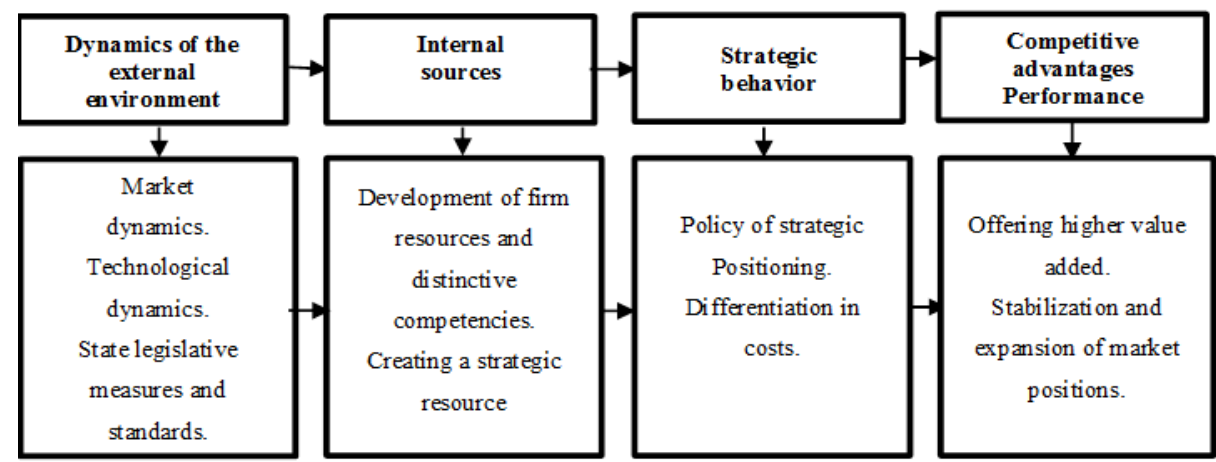

Fig.3. A model of building competitive advantage in a moderately dynamic, oligopolistic market (civil engineering market), which implies a policy of strategic positioning and differentiation in costs

\section{CONCLUSION}

In today's dynamic environment, research focuses on strategic behavior and the building of competitive advantages as a function of two factors: 1) the role and influence of the dynamics of the external environment (market), and 2) the development and change of company resources and competences under the influence of external changes. In order to analyze and evaluate the influence of the dynamics of the external environment on the strategic corporate behavior, the author develops and tests a conceptual model "Dynamics of the external environment (market) - Strategic behavior Competitive advantages", to study the activity of several companies working on civil engineering market and building construction market, with different dynamics, offering different product to different clients. The basis for the analysis, testing of the model and the defined hypotheses and the relevant conclusions is the collected information from the managers, employees in the studied companies, the aim is to reveal the relationship between the four variables: 1) Environmental dynamics, 2) Strategic behavior, 3) Firm resources and distinctive competencies, 4) Competitive advantages and performance. The starting point in the research process common to all companies, with different dynamics 
of the external environment is the analysis of changes, assessment of the possibilities for reconfiguration of resources, the need to absorb new knowledge, learning, integration and coordination in the company, which will ensure the achievement to the end point of this chain - building competitive advantages and performance. The study proved the working hypotheses:

1) The dynamics of the external environment (market) have a right, positive connection and influence on the strategic behavior of the firm. Managers of firms, operating in the civil engineering market define the market as a moderately dynamic, oligopolistic market characterized by a stable industry structure, relatively stable horizontal and vertical boundaries, a stable number of competitors, consumers, suppliers, clear and predictable behavior of participants. In these markets, the strategic behavior of the company is realized through detailed, analytical procedures and routine actions, the result of accumulated experience, knowledge and sufficient information.

Managers of firm, operating in the building construction market define the market as volatile, rapidly changing, without a clearly defined market structure, delineated borders, participants (competitors, users, suppliers, etc.) are constantly changing, with an unclear profile, unknown actions and reactions. Under these conditions, it is difficult to analyze and evaluate the situation and make well-considered decisions. Uncertainty does not allow the creation and implementation of a long-running model for a longer period of time, albeit with appropriate variations.

The combination of market (degree of uncertainty) and technological (degree of complexity of connections in the industry) dynamics creates different opportunities for company development and strategic behavior. The low degree of uncertainty, combined with the low degree of complexity of relationships, implies stability and a diversification strategy based on low costs and cost differentiation. The dynamics of the external environment exacerbates the instability of the market, which requires the company to develop its innovative activity - to improve and create new products.

2) Testing the second hypothesis proves that the dynamics of the market have rights, a positive connection and influence on the development of company resources and distinctive competencies and the creation of a strategic resource. Changes in demand and technology, shortening the product life cycle, increasing global competition increase the dynamics of the external environment and reduce the value of the created strategic resource in the company, but also create the conditions for development, change and creation of a new strategic company resource.

3) Testing the third hypothesis proves the relationship between resources, competencies and the external environment, which determines the strategic choice of the company, its positions and competitive advantages - differentiation in the product or differentiation in costs and performance. Analysis of the dynamics of the external environment and internal sources and factors for building competitive advantage

allows the author to develop two example models of building competitive advantages that take into account the specifics and dynamics of the external environment in which the company operates.

The proposed research and the model developed help managers to better understand the dynamic conditions in which they work and, on that basis, to determine effective strategic behavior in order to build competitive advantage and performance. The study also proves that the success of each company is a function of expediency (strategic behavior must be consistent with the dynamics of the external environment), timeliness (the speed at which they change, realigning the company's resources and competencies) and efficiency (the end result - built competitive advantage). 


\section{REFERENCES}

[1] Barney J. (2001), Resource-based theories of competitive advantage: A ten-year retrospective on the resource-based view, Journal of Management, 27(6), pp.643-650

[2] Barney J., \& Clark D. (2007), Resource-Based Theory: Creating and Sustaining Competitive Advantage, Oxford: Oxford University Press

[3] Eisenhardt K., \& Martin J. (2000), Dynamic capabilities: What are they?, Strategic Management Journal, 21(10/11), pp. 1110-1114

[4] Helfat C., Finkelstein S., Mitchell W., Peteraf M., Singh H., Teece D., \& Winter S. (2007), Dynamic capabilities: Understanding strategic change in organizations, London: Blackwell

[5] Henderson B. (1989), The Origin of Strategy, Harvard Business Reyiew, 67(6), pp.139143

[6] Ivanova, V., Slavova, I. (2018) Ecological transformation in Bulgaria - new challenges to the businesses and the government, European Journal of Economics and Business Studies, v. 4, n. 2, p. 22-34. http://journals.euser.org/index.php/ejes/article/view/3425

[7] Marichova A. (2018), Building Strategic Resource - A Factor for the Competitive Advantages of the Construction Firm, Civil Engineering Research Journal, 5(5), CERJ RA-18-765, ISSN: 2575-8950

[8] Radix S., Sucherly, Faisal A., \& Imas S. (2016), The Influence of Market Attractiveness and Dynamic Capability on Competitive Strategy and the Implications on Business Performance of Creative Industry in West Java, SEAJBEL,Vol.11, Issue 2 (Dec.), ISSN 2289-1560.

[9] Teece D., Pisano G.\& Shuen A. (1997), Dynamic capabilities and strategy management, Strategic management Journal, vol.18, N7, pp. 509-533

[10] Wang C., \& Ahmed P. (2007), Dynamic capabilities: A review and research agenda, International Journal of Management Reviews, 9 (1), pp. 44

\section{Note:}

Aneta Marichova - University of Architecture, Civil Engineering and Geodesy, 1, Hristo Smirnensky Boulevard, 1046-Sofia, Bulgaria (e-mail:aneta.marichova@abv.bg, marichova_fte@uacg.bg) 